\title{
The Multiproblem Neighborhood Project
}

\author{
William C. Rhodes, Ph.D. \\ Jules Seeman, Ph.D. \\ Charles D. Spielberger, Ph.D. \\ Robert F. Stepbach, ${ }^{1}$ Jr., Ed.D.
}

\begin{abstract}
This is a brief report on a Multiproblem Neighborhood project in a moderate size metropolitan community. It presents the conceptual frame of reference of the project and some of the tangible organizational outgrowths of the research penetration into the complex community structures enclosing the neighborhood.
\end{abstract}

This paper is a conceptual analysis of a research demonstration project which explored and attempted to influence the humantrouble handling machinery of a community. The project, which focused upon a multiproblem neighborhood, served as the behavioral science resources of the university and the human-disruption control machinery of the community. However, in addition to its transmission function, the project had a significant generative function in both of these separate systems. The project pivoted around a demographic data-gathering effort which was an important aspect of its existence. This data will be published separately in a later report; our purpose here is to set forth a conceptual model which has generality beyond the project itself.

\section{Conceptual Overview}

A Macrosystem Model

The project was based upon the concept that community agencies and human-service programs function not only to help people in

1. Dr. Rhodes is Professor of Psychology in Community Psychology, the University of Michigan, Ann Arbor, Michigan. Dr. Seeman is Professor of Psychology, George Peabody College, Nashville, Tennessee. Dr. Spielberger is Professor of Psychology and Director of the Training Program in Clinical Psychology, Florida State University, Tallahassee, Florida 32306. Dr. Stepbach is in private practice in Clinical and Consulting Psychology, 1920 Church Street, Nashville, Tennessee 37203, Director, Neighborhood Counciling Center, 701 South Seventh Street, Nashville, Tennessee 37206 and senior clinical psychologist, 2410 White Avenue, Nashoille, Tennessee 37204. 


\section{Community Mental Health Journal}

trouble but also to protect the community against the perceived threats of problem-producers. The agitated encounters between stress excitors and strain-respondent segments of the community were our subject matter in a macrosystem that involved a number of different components:

I. Enclaves of psychocultural stressors or threat-elicitors in the larger community; that is, the multiproblem neighborhoods;

2. A community interlace of specialized threat-respondent units (the community agencies) that act in concert with;

3. The power structures of the community (governmental and specialized human-service agencies) in behalf of the general public who constitute the strain-respondent groups of the community.

This self-maintaining macrosystem of community threat and response may be construed as resulting from the gradual institutionalizing or hardening of a widening cleavage between the life history of individuals and the cultural history of the community. In order to clarify the elements of this conceptual model and the linkages among them, it is necessary to offer a brief description of each of the three units.

The multiproblem neighborhood. This consists of area clusters of threat-elicitors who are inadequate, emotionally disturbed, economically deprived, or who have frequent physical health emergencies or difficulty with the law, etc. The major groups of the community respond to personal-social disruptions in these areas as though a strain was being placed upon the collective community. Thus, the threat elicitors constitute a catabolic force in community living that heightens cleavages within the community.

The culturing institutions. In this particular model of ecological disruption-response, the disruption-handling elements of the culturing institutions constitute the defense machinery which is erected against a perceived danger. Operational patterns of social welfare, legalcorrection, mental health, public health, education, housing, recreation, and religion all contribute their share to this defensive array. Varying portions of the resources and culturing forces of these social institutions are devoted to the defensive task.

The power structures. All of the defensive patterns of the community interlock with the power structures of the community to prevent major disjunctions between the individual and collective living. Some of the personal social disruptions to which this machinery responds, such as mob violence, may constitute real dangers to group living. Others, such as homosexuality, may be remnants of a past historical period. For the latter, the actual threat may not justify the institutional response.

Linkages in the Disruption-Handling Machinery

Since the executive direction of the trouble-handling 
or disruption-control machinery is rarely located at the neighborhood level, the mobilization and deployment of the neighborhood forces are directed from an echelon outside the neighborhood context. The decision-making apparatus of the disruption-handling machinery is generally made up of agency executives and their boards. The agency executives are linked to the community power structure through liaison with the executive, judicial, and legislative branches of government. They relate to the informal power structures of the community through their own policy-making boards.

In collaboration with the formal and informal power structures, the disruption-handling machinery of the community defends against collectively real and fantasied threats from the disruption-producing neighborhoods. These power structures are the seat of the major decisions about when, how, where, and how much of the community's resources will be mobilized and deployed in front-line defense against particular threats at the neighborhood level. While there is some autonomy at each level of the defensive machinery, much of the strategy is determined and directed from the upper echelons, particularly at the level of executive, legislative, and judicial governmental organization. These determinations usually are consolidated into laws which form the basis for community relationships with the disrupting populations.

In order to enter this total human control system and insure its cooperation at the neighborhood level, it is generally necessary to obtain the sanction of the upper agency echelon as well as the relevant, formal, and informal power structure levels. Whatever is done at the neighborhood level is quickly communicated up the communication lines of the system, and if an action is perceived as inimical to the directions and decisions of the upper echelons, it is likely to invoke resistance and rejection.

Therefore, unless one is prepared to meet and overcome such resistance, or to work outside the human disruption system and its sanctions, it is necessary to achieve and maintain the approval of the community power structure for one's operations.

Guided by this macrosystem model, the project not only concentrated upon a particular multiproblem neighborhood but also devoted considerable time and negotiation at two other crucial entry points into the system of disruption control, namely, the executive branch of local government and the executive units of the major disruption control or threat-respondent units such as police, welfare, education, health, etc. This was seen as a necessary part of the project and influenced both staffing and organization of the project structure.

\section{The Problem Unit}

The major conceptual difficulty was, from the very beginning of the project, the nature of the disruptions which were the focus of concern. The pivotal concept with which the project began was that of "dis- 
cordance." Initially the phenomenon which was to have our major attention was described as "discordant behavior." This term was used to bracket a number of psychosocial problems which seemed related to each other and to the debilitating conditions of a "slum" habitat. Discordant behavior included delinquency, alcoholism, psychosis, crime, desertion, etc., as well as any other behaviors and patterns of living that were discordant with the standards of the community.

We recognized, of course, that the concept of discordances implies culturally relative terms. "Delinquency," for example, might be defined differently in two different communities, according to the local legal code. To meet the problem of relativeness, we used the term "discordant behavior" to refer to specific episodes or incidents. These episodes were defined in terms of a traumatic human event which elicited a response from one or more of the community agencies established by society to deal with that class of upsetting human events.

Thus, for our purpose, the response by an appointed agent of the community was the operational definer of an event as discordant with community behavioral standards.

Two problems were encountered in the use of the discordance concept. One problem was that some of the human events which aroused agency response did not conform to the discordance concept in that they did not violate community norms, taboos, or sanctions. Many simple life episodes, such as a loss of a pair of glasses by an elderly resident of the community, were judged as significant disruptions by the official agent; whereas, in the beginning, it seemed almost irrelevant to the study group.

A second problem concerned the relativity of the discordance concept. It was surprising how perspective and base lines shifted once the study group became immersed in the culture of the neighborhood. What seemed dissonant or discordant prior to such immersion became a normal way of life or a normal part of life after immersion.

After the pilot data were collected, studied, and analyzed, it became evident that the episodes, which had been collected through the wide net of the total gamut of neighborhood based community agents, were stretching the limits of the working concept. Discordance, as the major concept, did not capture the full range of the data. The life happenings within the neighborhood which activated agencies or which demanded community response were definitely within the realm of personal-social disruptions, but they were of a wider ecological nature. While they all had psychosocial repercussions, not all of them were psychosocial in essence.

An arbitrary choice could have been made to include only episodes of a psychosocial nature, but then much rich and significant data would have to be ignored. Furthermore, these psychosocial disruptions were entwined within a nest of disruptions, so that it was very hard to separate them out as a pure case of the class we wanted. Even more important, an episode fre- 
quently had a fluidity that would not permit the time-demarcation of a beginning and end which would separate off the psychosocial from the physical, the economic, the legal, etc. Like a chameleon, an episode frequently reflected different colors from moment to moment or even at the same moment "en situ," so that it was hard to pin it down into an unchanging class. It became important, therefore, to shift to an ecological frame of reference and to a concept of a normal, but fluid, individual and group functioning within the neighborhood and family milieu.

Therefore, at the point of the collection of the first-run data, the concept of Ecological Disruption seem to be more useful. "Ecological" signified the relationship between the individual and his environment and between persons and community. An ecological disruption was defined as any humancentered event that interrupted the relative steady state of the neighborhood to such an extent that it elicited a response from a local caretaker. Thus, each recorded event had two sets of terms-the excitor terms and the respondent terms, and each recording of an ecological disruption specified properties of both the excitor and the respondent.

\section{Project Overview}

The Neighborhood Site Focus

Before going further into a description of the project, the authors acknowledge the limitations of their approach. It is recognized that to look at the process of individual disruptions and community response is merely to view the existing practices and problem-conceptions of communities. It does not uncover more significant or neglected human problems in these zones of problem concentration. However, this approach did engage the macrosystem of disruption handling, while avoiding collision or conflict with the system, and it allowed us to move inside the system and observe and record its operations first hand.

The geographical unit chosen as the site for recording and mapping these excitor-respondent episodes was a multiproblem or high-disruption producing neighborhood with a high concentration of disruption-handling machinery. The machinery consisted of police, social welfare, housing, health, and other agencies. The area was one of three trouble-producing neighborhoods in the community in a moderate size metropolitan area of 460,000 population. It was selected on the basis of the following criteria: (a) contain a high density of indigenous multiproblem behavior; $(b)$ manifest high community agency involvement; $(c)$ be predominantly a single race neighborhood; $(d)$ contain a public low-rent housing project; $(e)$ contain a community center; $(f)$ be accessible to the university, and limited in areas so that it can be covered on foot.

The first two criteria comprise the major components of the study and are obviously required. Criterion $c$ was included to limit the number of variables to be studied. Criterion $d$ was included because it had been ob- 
served that multiproblem families and associated agency involvement are concentrated in public housing projects. Criterion $e$ was included because of its strategic value as a base of observation. The final criterion was directed toward the question of accessibility and efficiency of staff utilization.

\section{The Project Apparatus}

The project brought together university resources on one hand and representatives of the disruption-handling machinery of the community on the other. On the university side there was an advisory group and a project director. Represented in the university segments were:

1. The sociology and psychology departments of one institution.

2. The psychology department of a second institution.

3. The department of psychiatry at a third.

4. Staff members of the community's mental health center.

On the community side, the involvement included:

1. The congeries of neighborhood based operations of the human service agencies (representing the "caretaker" group).

2. The executives and their boards in the official disruption-handling machinery of human-service agencies. (The middle management group).

3. That part of the official community power structure devoted to the handling of disruptions between individuals and community.

The representatives of the university had several functional connections with various levels of the community disruption-handling machinery. University faculty were on various committees of the governing body of the city, and on various committees established for the regular functioning of the middle-management group in executive control of the agencies. In addition, each of the executives of the agencies with official responsibility for disruption-control were formally contacted and involved in the project. Some of these executives served for varying periods of time and for specific purposes on the Directorate Group of the project. The agencies included health, mental health, education, welfare, housing, etc.

\section{Neighborhood Level Procedures}

At the neighborhood level, a full-time and a half-time participant-observer were the mainsprings of the project throughout the full year. The full-time neighborhood paricipant-observer was an advanced student with training in psychology and sociology. The half-time participant-observer was an experienced degree psychologist on the staff of the local mental health center with responsibilities as a clinician and a community consultant. He was well known in the community and had a wide- 
range of established relationships with all levels of the disruption-handling machinery.

The two key project staff members functioned in the neighborhood in a semiautonomous role. That is, they were identified as project personnel associated with a study conducted from the university center, and they also established loose ties to the caretaker group in the neighborhood. Their major identifiable relationship unit was a Neighborhood Council of the caretaker group.

Considerable time was spent in the initial stages of the project just "hanging around" in the neighborhood. The two participant-observers also moved around the neighborhood streets, hang-outs, and institutional centers. They became familiar with the ministers, police, housing authorities, health workers, case workers, barbers, tavern-keepers, etc. In addition to their movable office, they also had space in the local community center (settlement house).

Once the top agency directors of the "middle-management" group, and the mayor's office in the upper-management group had sanctioned the project, each of the caretakers in the neighborhood was contacted on an individual basis. In addition, the project was explained and discussed with the Neighborhood Council.

The major means of initial data collection was a routine intelligencegathering route traveled daily and/or weekly by one of the participantobservers. In the latter research phases, this method was abandoned for a more rigorous and controlled procedure. The senior participant-observer found himself drawn into frequent consultation to the caretaker groups in neighborhood. Although this was not a planned part of the project, it had been anticipated and was acknowledged to be a necessary reciprocity for the time and interest given the project by the caretaker group. Both the data gathering and the consultation provided a continuing, reciprocal, mutually advantageous relationship between the project and the caretaker group.

\section{A Human Culturing Concordat}

Through the two linkage agents, the resources of the universities complex and the resources of the total community disruptioncontrol apparatus were provided with a temporary coupling system. Through this coupling system and this operational focus upon a commonly shared problem, a back-and-forth flow between the two entities was established.

Some of the operational patterns created out of this interchange are discussed below. For the present, however, reflection upon this process suggests that the only additional ingredients needed to consolidate these taskfocused alliances into a joint operational organization of some endurance would be: $(a)$ a stated agreement between the working parties and $(b)$ continuity in funding sources. These ingredients can translate the task-focused 
cooperative endeavor into almost any desired form of intermediate agency between the university and community machinery, so long as it does not violate the established investments of either party to the agreement.

If our observations are valid, this suggests that it would be possible to establish a blending station or operational center which could channel and provide the appropriate interflow between the human science resources of the university and the disruption-control resources of the community toward specified human culturing ends. Such a center could act as an intermediate switching station between the conceptual and problem-solving skills of the university and the caretaking attitude and functions of the disruption-control machinery. At the same time it could offer a community observatory or laboratory for research and training programs of the university.

In our particular project, the joint endeavor of data-gathering and the two linkage agents accomplished this type of exchange and institute pattern. On one side was the Project Directorate which utilized university faculty from three institutions and four human science departments, and on the other side was the Caretaker Council of the neighborhood and the loose working relationships that were developed with agency executive and the mayor's office. As indicated earlier in this report, although the project focused its efforts upon the neighborhood site, it also devoted considerable time throughout the project period to the other two levels of executive structures mentioned above. We continued to take the position that the disruption-handling network formed a total community Gestalt which was administratively connected in ways not obvious to the outside researcher, and that a research-focused entry point into this network was likely to be felt and known (and possibly resented) by the other parts of the total machinery.

The experience of this temporary coordinate coupler between the university and the disruption control machinery provides suggestions for the multiple ways in which such an interlocutor mechanism might become a generator of evolution and change in the culturing media of communities. Some of the generative effects produced by this project included the following:

I. Sparked a special neighborhood problem-solving subgroup or changeagent committee of the Neighborhood Council of caretakers.

2. Provided the nucleus of a branch unit of the mental health clinic especially designed to reach out into the poverty area and the target population of the poor.

3. Implanted the embryo of a University Center for Community Studies.

4. Provided a psychosocial laboratory in a slum area within which advanced graduate students could obtain supervised Community Psychology experience. 
These ripple effects of the project are its most tangible community results. They evolved out of the research-focused exchanges of the university and community groups and are having generative effects of their own upon both the excitor or stress-inducing populations and the disruption-handling machinery of the community. They are also having feedback effects upon the university center.

In order to provide a better grasp of each of these direct organizational outcomes of the project, a brief description of each is given below.

\section{The Neighborhood Change Agent Committee \\ The "Change Agent Committee" of the Neighborhood} Council arose out of the revitalized interest of the Council members in neighborhood planning. A small number of members formed a subgroup of the Council and agreed to meet weekly for lunch and discussion. The Committee has been and is presently composed of the following types of caretakers: a public housing project manager, the director of a neighborhood settlement house, a housing project social service worker, a public welfare worker, a psychiatric social worker, and a clinical/community psychologist. Additional professional people have met with the group from time to time to help the Committee clarify issues in which there was a lack of competency. An example of one such meeting was a lengthy discussion with an attorney during which time he expertly discussed in lay terms the social dilemmas of legal aid, divorces for the poor, garnishment, bankruptcy, loan practices, usury, and more.

Currently, the Committee has proposed a twofold plan for neighborhood action. First, they intend to emphasize the development of self-governing and self-determining groups. People with problems will be the problem solvers whenever possible. Experts will be used to facilitate this process as necessary. Increased socialization and the restoration of self-dignity and purpose are the obvious goal of this part of the plan.

Secondly, increased communication among agencies serving the neighborhood has been planned. A workable, neighborhood central clearing house for problem families has been proposed out of which coordinated service and planning can emanate. In addition, a serious effort will be made to ask and provide answers to "researchable" questions. For example, by studying gaps in agency services and families who fall through the "cracks," it is hoped that meaningful data will be provided the policy-making bodies of the community. They, in turn, can generate sound legislation which will enhance the welfare of the neighborhood.

It is apparent that the Neighborhood Council has become more than a monthly meeting of caretakers offering mutual emotional support in the face of overwhelming professional problems. It has become a springboard for social action, a kind of middleman between the clients and the agency policy makers who spell out the types of services offered to those clients. 


\section{Community Mental Health Journal}

\section{Branch Neighborhood Counseling Center}

The branch unit of the Mental Health Center is calling itself a Neighborhood Counseling Center in order to minimize the fear and avoidance people feel about mental and emotional problems. The staff consists of a resident (Negro) psychiatrist from a local medical school, a clinical psychologist, two psychology interns, three psychiatric social workers, and two second year students in social work. The unit is housed in the Manager's Office of the local public housing project. It operates on a half-time basis.

The branch clinic has the task of finding out why the lower class does not use the traditional mental health services in the community. At this stage, a large portion of time is spent in consultation with neighborhood caretakers and community planning. Therapeutic endeavors are experimental, flexible, and adapted to the needs of the person or persons in trouble. An attempt has been made to make treatment a part of the dynamic social process of the neighborhood rather than an isolated phenomenon in a strange office across town.

\section{The Proposed Center for Community Studies}

It became clear that the current time-limited project was only one of many possible prototypes for community-oriented research. The conviction grew among the staff that a more permanent organization was needed to bring a behavioral science capability to bear upon community problems. From this conviction grew the idea of a Center for Community Studies.

The purpose of the Center would be to foster inquiry and experimentation in community behavioral processes. The interest areas of the Center would be broad enough to include those community processes where human effectiveness may be enhanced-for example, delinquency, social disorganization, emotional disturbance, poverty, educational problems, and the like.

The foregoing objective makes it clear that the Center's domain of concern would require a broad interdisciplinary research approach. It is envisioned that the staff and consultant organization initially would include at least the disciplines of sociology, psychology, psychiatry, and anthropology. The principle of the Center's staffing would be that the Center could call upon broad knowledge in the behavioral sciences for the studies. 